\title{
Design of Vibrate Generator
}

\author{
Nur Untoro \\ Physics Education Department Faculty of Science and Technology, UIN Sunan Kalijaga, \\ Jl. Marsda Adisucipto No 1 Yogyakarta 55281, Indonesia. Tel. +62-274-540971, Fax. +62-274-519739. \\ Email: nuruntorobinjamanin@ychoo.co.id
}

\begin{abstract}
Untoro N. 2017. Design of Vibrate Generator. Proc Internat Conf Sci Engin 1: 205-208. Vibrate generator is an electric generator, which generate electric by a magnet vibration. This research inspired by the discovery of windbelt by Humdinger. The purpose of this research is to prove electric generator with magnetic vibration, to design low rpm vibrate generator. Electric generator in this vibration is simple, expected to be made society with local material. With an energy source from a ditch drainage or wind, this generator are supposed to generate electricity for one house. Major component generators are bar magnets, springs, wire coils, diode, capasitor and wood board. The principle of generator unit is a magnet attached to the spring and the end of the spring attached to the wooden board. If the spring is vibrated, magnetic vibrations produce a magnetic flux change that penetrates the wire coil who attach beside a magnet. A wire coil penetrated flux magnetic which change with time to produce electro motive force. Every unit generator produce AC and changed to DC by Diode Bridge. The experiment results were one unit cell generator produce 2.2 volt peak to peak, $21.47 \mathrm{~Hz}$, and product duration 0.5 second. The design of a low rpm vibrator generator is built from a vibration generator unit arranged and connected in parallel. Each unit vibration generator is vibrated sequentially, in order for a continuous power generation.
\end{abstract}

Keywords: Electric generator, local material, low vibrate generator, magnet vibration, vibrate sequentially

\section{INTRODUCTION}

Humdinger (2004) discovery of windbelt (Logan.2007), is a flutter ribbon attached to magnet which induce the coil to produce electro motive force. Humdinger invention inspiring writer to make vibrate generator. There are three methods for harvest vibration energy: electromagnetic, piezoelectric, and electrostatic (Dibin, 2011). This research is preliminary research about vibrate generator. In this research we used electromagnetic vibration harvester. Spring mass system will vibrate if we hit it. The vibration or oscillation will last for some time, who can harvest electric energy.

Vibrate generator is electric generator, which generate electromotive force by a magnet vibration. Basic principle of vibrate generator is vibrate of a magnet between two coil. The magnet attach at steel plate as spring which oscillate when it the end is beaten. Vibrate or Oscillation of magnet make flux magnet linkage the coil is Oscillation too. The change of flux magnet in to coil produce electromotive force (induction faraday law):

$$
\varepsilon=-N \frac{d \Phi}{d t}
$$

Oscillation of mass spring

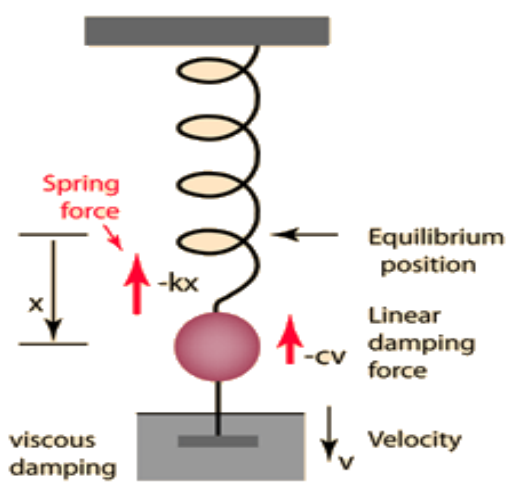

Figure 1. The Underdumped oscillation of a spring.

The Newton's 2nd Law motion equation is (hyperphysics. 2016)

$m a+c v+k x=0$

$m \frac{d^{2} x}{d t^{2}}+c \frac{d x}{d t}+k x=0$

This is in the form of a homogeneous second order differential equation and has a solution of the form

$x=e^{\lambda t}$

Substituting this form gives an auxiliary equation for $\lambda$

$$
m \lambda^{2}+c \lambda+k=0
$$


The roots of the quadratic auxiliary equation are

$\lambda=\frac{-c \pm \sqrt{c^{2}-4 m k}}{2 m}$

The three resulting cases for the damped oscillator are (hyperphysics. 2016)

$$
\begin{aligned}
c^{2}-4 m k>0 & \text { Overdamped } \\
c^{2}-4 m k=0 & \text { Critical damping } \\
c^{2}-4 m k<0 & \text { Underdamped }
\end{aligned}
$$

- Overdamped if coefisient of viscous damping is very large, mass move slowly to equlibrium. There is no oscillation.

- Critical damping if coefisient of viscous damping is balance with restoring force, massa move rapidly to equlibrium. There is no oscillation.

- Underdamped if coefisient of viscous damping is small, mass oscillated with degradated amplitude.

In the mass-spring electromagnetic system.

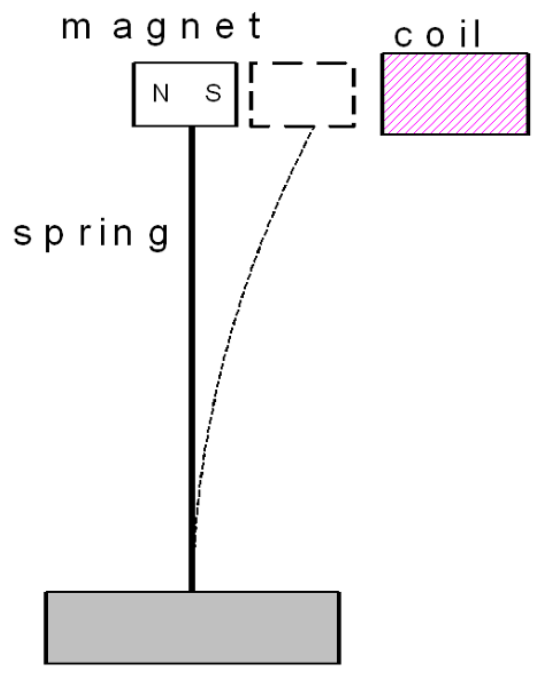

Figure 2. Oscillation of a Magnet on the spring.

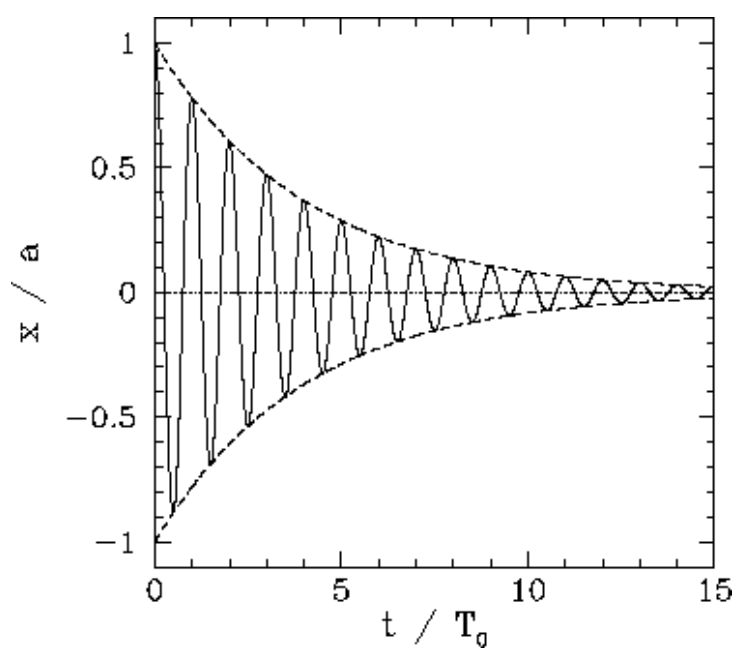

Figure 3. Damped harmonic oscillation.
Dumping from electromagnetic force:

$$
\vec{F}=q \vec{v} \times \vec{B} \quad \text {, in the case } \mathrm{v} \perp \mathrm{B}
$$

$F=q v B=q B v$

The constan force $c=q B$. $\mathrm{q}$ is the total charge who move in coil, is proportional with current I.

When a damped oscillator is subject to a damping force which is linearly dependent upon the velocity, such as viscous damping, the oscillation will have exponential decay terms which depend upon a damping coefficient. If the damping force is of the form

$F_{\text {dumping }}=-c v$

Then the damping coefficient is given by

$\gamma=\frac{c}{2 m}$

Where $\gamma$ is damping coefficient

This will seem logical when you note that the damping force is proportional to c, but its influence inversely proportional to the mass of the oscillator.

Underdamped Oscillator

The underdamped response of the oscillator is described by equation:

$$
x(x)=a e^{-\gamma t} \cos \left(\omega_{1} t-\alpha\right)
$$

With $\omega_{1}=\sqrt{\omega_{0}^{2}-\gamma^{2}}$

$\omega_{0}=\sqrt{\frac{k}{m}}$, the harmonic frequency

The amplitude of dumped oscillator is reduce exponentially with time. Generator need damping coefficient is small, so oscillate long time.

\section{MATERIALS AND METHODS}

To design a generator, we must know the characteristic and calculate how much electro motive force would produce.

To analysis, we assume that the coil is rectangle, the magnet vibrate parallel with coil surface, like Figure 4.

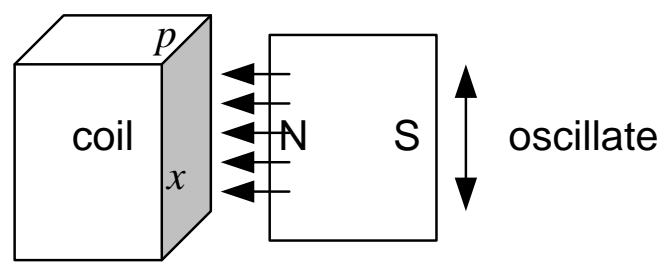

Figure 4. The magnet flux change in the coil. 
Electro motive force, induction Faraday Law:

$$
\begin{aligned}
& \varepsilon=-N \frac{d \Phi}{d t}=-N \frac{d(B A)}{d t}=-N B \frac{p d x}{d t} \\
& x(t)=a e^{-\gamma t} \cos \left(\omega_{1}-\alpha\right) \\
& \varepsilon=-N B p \frac{d\left(a e^{-\gamma t} \cos \left(\omega_{1} t-\alpha\right)\right)}{d t} \\
& \varepsilon=-N B p\left(-a \gamma e^{-\gamma t} \cos \left(\omega_{1} t-\alpha\right)-\omega_{1} a e^{-\gamma t} \sin \left(\omega_{1} t-\alpha\right)\right) \\
& \varepsilon=N B p a e^{-\gamma t}\left[\cos \left(\omega_{1} t-\alpha\right)+\omega_{1} \sin \left(\omega_{1} t-\alpha\right)\right] \\
& \text { If } t=t_{0} \text { phase } \alpha=0 \\
& \varepsilon=N B p a e^{-\gamma t}\left[\cos \left(\omega_{1} t\right)+\omega_{1} \sin \left(\omega_{1} t\right)\right]
\end{aligned}
$$

$\mathrm{a}$ is amplitude, and $p a$ is area of coil A.

$$
\varepsilon=N B A e^{-\gamma t}\left[\cos \left(\omega_{1} t\right)+\omega_{1} \sin \left(\omega_{1} t\right)\right]
$$

The vibrate generator design

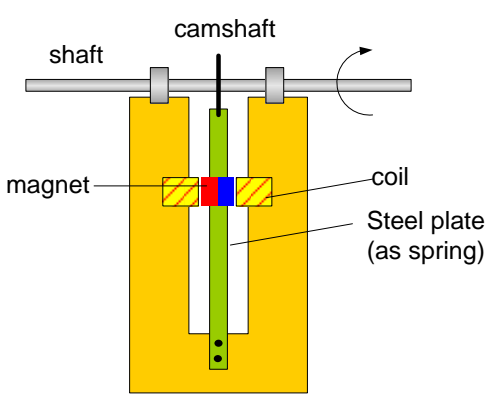

Front view

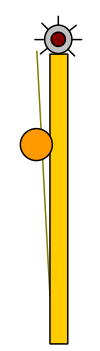

Side view

Figure 5. Basic Design vibrate Generator.

Table 1. Design a unit generator.

\begin{tabular}{ccl}
\hline No & Material & Dimension \\
\hline \hline 1 & Coil: wire & Diameter $0.15 \mathrm{~mm}$ \\
& Turn & 160 turn \\
2 & Magnet & $10 \mathrm{~mm} \times 15 \mathrm{~mm} \times 20 \mathrm{~mm}$ \\
& & Br $=1,2 \mathrm{~T}$ \\
3 & Spring & Metal Ruler \\
& & Length $: 15 \mathrm{~cm}$ \\
\hline
\end{tabular}

\section{Experiment:}

Connect the output of generator with the oscilloscope, and measure frekuensi and volt peak-to peak, and dumping coefficient.

\section{RESULTS AND DISCUSSION}

The unit vibrate generator is constructed by wood board, magnet, wire coil, spring, and shaft (Figure 5). If the end of spring is beaten, the spring and magnet would vibrate. Magnetic flux who penetrated in to coil would change with time and coil produce electro motive force. The coil output is alternating current (ac), with amplitude is reduce with time.

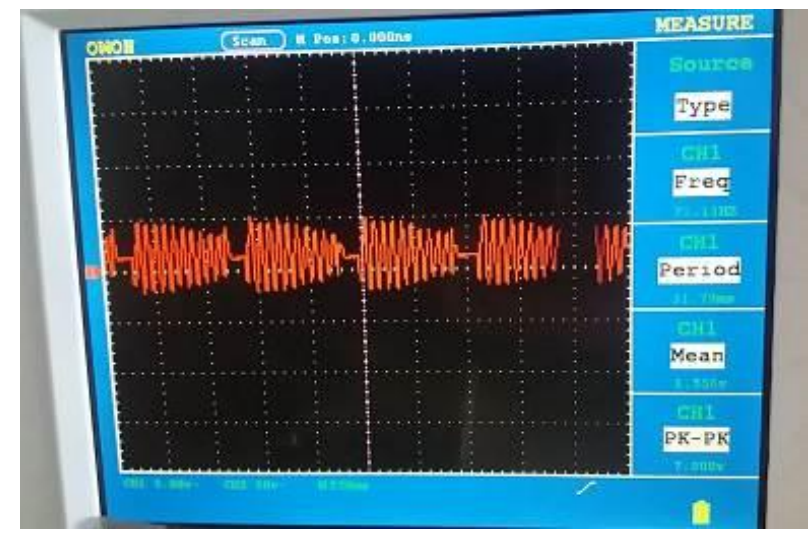

Figur 6. Output vibrate generator.

Output vibrate generator in Figure 6, frequency is $23.1 \mathrm{~Hz}$, voltage 7.2 volt peak to peak.

Output voltage propotional with turn number of coil $\mathrm{N}$, if we use magnet and the spring is not change, output voltage needed can calculated number turn:

$$
N_{\text {need }}=\frac{V_{\text {need }}}{V_{o}} \times N=\frac{V_{\text {need }}}{7.2 \text { volt }} 160 \text { turn }
$$

Amplitude reduce with time, output voltage $\mathrm{V}_{\mathrm{pp}}=7.2$ volt after $625 \mathrm{~ms}$ reduce to 3.6 volt, so damping coefficient $\gamma=1.1 \mathrm{~s}^{-1}$. The damping coefficient is very large, so amplitude reduce very quickly. We want the output voltage to be more than half the original voltage, then we take an active time interval of half a second. The spring generator must to vibrate every half second.

The generator output is ac rectified by Diode Bridge, and filtered by capacitor, become DC mode. Generator must produce continuous power, so the very low rpm generator is designed from some unit vibrate generator who arranged in parallel.

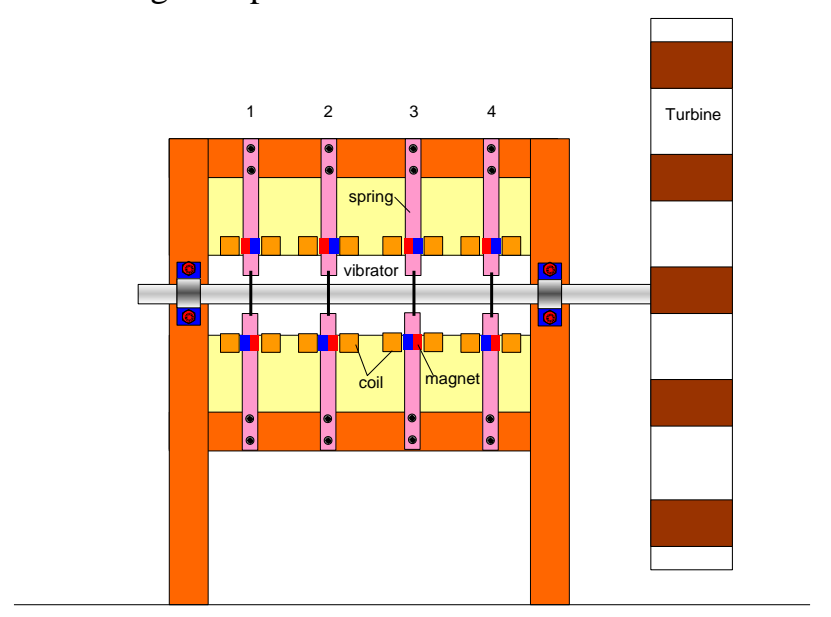

Figure 7. Very Low rpm Generator construct.

Camshaft every unit generator must to be set that vibration of the spring occurs sequentially from spring 1 , spring 2 , spring 3 , spring 4 and return spring 1 . Output 
every coil rectified and connected to battery like Figure 8.

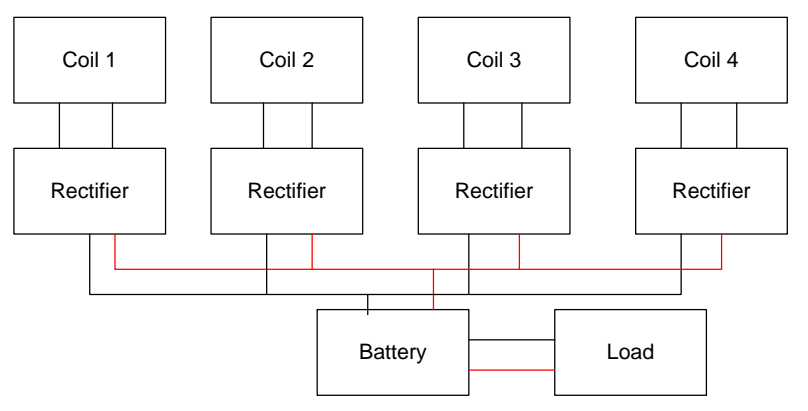

Figure 8. Circuit diagram

\section{Example Calculation:}

Vibrate generator is designed to be driven by ditch flow, flow rate water of ditch is $0.3 \mathrm{~m}$ per second and the radius of the turbine/water wheel is $70 \mathrm{~cm}$. So the water wheel period at about 16 seconds.

If we arrange 4 unit generator, every the spring vibrate 0.5 second, the period is $4 \times 0,5 \mathrm{~s}=2 \mathrm{~s}$. Water wheel saft period is 16 seconds, but periode of generator is 2 s. The solution for this problem is camshaft $16 / 2=8$ teeth. In one water wheel period there are vibrates 8 time spring of unit generator and total $4 \times 8=32$ vibrates of all the spring. The generator operate at 16 seconds period, so the generator low rpm and it driven without gearbox or direct drive.

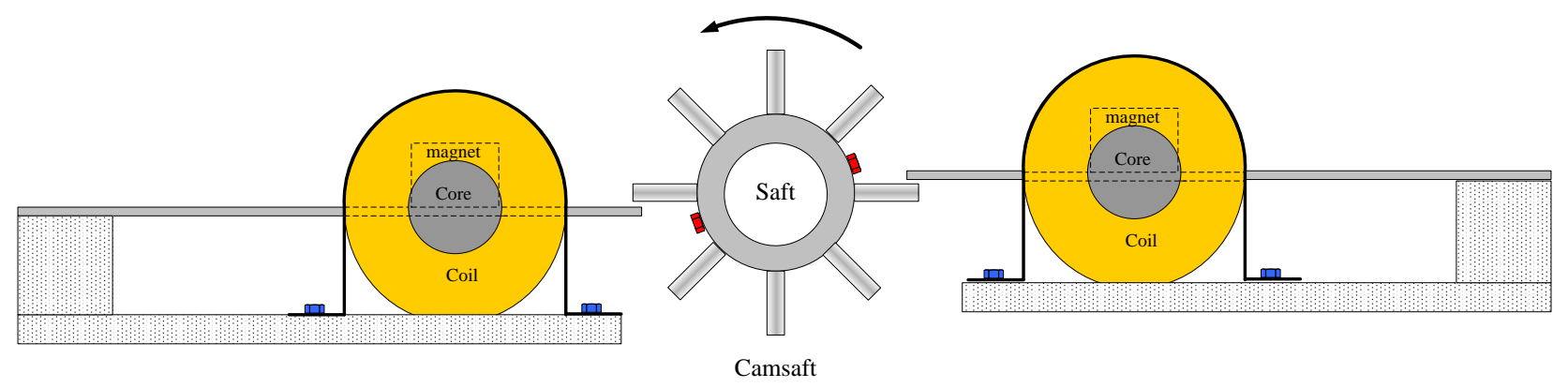

Figure 9. Generator Camshaft 8 teeth.

\section{Discussion}

The vibrate generator is a preliminary research, the calculation in the design is still limited to the resulting voltage, not yet related to the electrical power generated. Generator power is highly dependent on the spring potential energy, flux magnet, and coil dimension. Next study program is power vibrate generator.

Oscillation Damping coefficient $1.1 \mathrm{~s}^{-1}$ is very big, so amplitude reduce rapidly. That is bad characteristic for vibrate generator, because we use metal ruler as the spring. It needed the spring research for vibrate generator in order to obtain the spring with low dumping coefficient.

Based on the size of the spring used, this vibrate generator is low power with a power range of several tens of watts. Although generators are only capable of producing low power, this is much needed for the village community. The design of this simple generator is expected to be made by the community with locally available materials. Available energy sources, such as water or wind energy can be used to generate electricity with this vibrate generator. I hope every one in village community can use electric power.

\section{CONCLUSION}

The experiment results were one unit cell generator produce 2.2 volt peak to peak, $21.47 \mathrm{~Hz}$, and product duration 0.5 second. The design of a low rpm vibrator generator is built from a vibration generator unit arranged and connected in parallel. Each unit vibration generator is vibrated sequentially, in order for a continuous power generation.

\section{REFERENCES}

Hyperphysics. 2016. Departement of Physics and Astronomy Geogia State University.www. http://hyperphysics.phy-astr. gsu .edu/hbase/oscda.html

Logan Ward. 2007. Windbelt, Cheap Generator Alternative, Set to Power Third World. www.popularmechanics.com/ science/energy/a2152/4224763/

Zhu, Dibin. 2011. Vibration Energy Harvesting: Machinery Vibration, Human Movement and Movement and Flow Induced Vibration In, Tan, Yen Kheng (eds) Sustainable Energy Harvesting Technolog ies-Past, Present and Future. INTECH pp 25-54 